\title{
High-sensitive basal serum thyroglobulin 6-12 months after thyroid ablation is strongly associated with early response to therapy and event-free survival in patients with low-to-intermediate risk differentiated thyroid carcinomas
}

\author{
P Trimboli', V Zilioli ${ }^{2}$, M Imperiali ${ }^{3}$, L Ceriani ${ }^{1}$ and L Giovanella ${ }^{1,3}$ \\ ${ }^{1}$ Department of Nuclear Medicine and Thyroid Centre, Oncology Institute of Southern Switzerland, \\ Bellinzona, Switzerland, '2Department of Nuclear Medicine, Bolzano Regional Hospital, Bolzano, Italy, \\ and ${ }^{3}$ Department of Laboratory Medicine, Ente Ospedaliero Cantonale, Bellinzona, Switzerland
}

Correspondence
should be addressed
to P Trimboli
Email
pierpaolo.trimboli@eoc.ch

\begin{abstract}
Objective: High-sensitive thyroglobulin assays (hsTg) has decreased the need for stimulated Tg measurements in patients with differentiated thyroid carcinoma (DTC). However, multiple assays analyzing the same samples may report different values. Accordingly, appropriate assay-specific cut-off levels should be selected in representative patient series. Here, we evaluate the role of a new hsTg assay in low-to-intermediate risk DTC patients and select appropriate assay-specific clinical cut-off limits.

Design: This was a retrospective study. The response to treatment was assessed according to ATA.

Methods: Patients with low-to-intermediate risk DTC treated and regularly followed-up in our thyroid center. Tg was measured on the Kryptor Compact Plus Instrument (BRAHMS Thermo Fisher Scientific).

Results: The study series comprised 201 DTC patients and excellent response (ER) was demonstrated in 184 (91.5\%).

Optimized threshold of basal Tg (onT4-Tg) measured 6-12 months after initial treatment was set by ROC curves analysis at $0.28 \mathrm{ng} / \mathrm{mL}$. Having onT4-Tg $<0.28 \mathrm{ng} / \mathrm{mL}$ at $6-12$ months after treatment was associated with longer disease-free survival of Kaplan-Meier $(P<0.001)$, ER at early follow-up (odds ratio (OR): $165, P<0.001)$ and absence of relapse during follow-up (OR: $328, P=0.0001$ ).

Conclusions: Patients with low- and intermediate-risk DTC could be considered cured when they have onT4-Tg levels $<0.28 \mathrm{ng} / \mathrm{mL}$ coupled with negative imaging at their first post-ablation visit.
\end{abstract}

\section{Introduction}

Differentiated thyroid carcinoma (DTC) is an endocrine tumor with a favorable outcome and 10-year survival rates of $80-95 \%$ (1). According to American Thyroid Association (ATA) guidelines, patients are classified into low-, intermediate- and high-risk groups depending on
() 2017 European Society of Endocrinology Printed in Great Britain their risk of recurrence and death (2). Traditionally, the treatment of DTC includes total thyroidectomy, and neck dissection when necessary, plus a risk-adapted radioiodine ablation (RRA) and lifelong therapy with levothyroxine (T4). Most low-risk and intermediate-risk 
DTC patients achieve excellent prognosis and a normal life expectancy (3); cancer recurrence may occur; however, in up to $20 \%$ of DTC patients, mostly in the local regional lymph nodes and within the first 5 years since initial treatment (2). Accordingly, regular follow-up is advocated in all DTC patients (2). However, it was proved that high-risk DTC patients achieve excellent prognosis and a normal life expectancy if excellent response to the treatment is achieved within 6-12 months after treatment. This approach (i.e. dynamic risk stratification system) allows tailoring follow-up intensity on an individual basis according to the response achieved after primary treatment (4). Currently, serum thyroglobulin (Tg) measurement and neck ultrasonography (US) are the mainstays in DTC patients' follow-up. Traditionally, at the time of first response to treatment assessment (generally within 6-12 months after primary treatment) serum Tg is measured after TSH stimulation (obtained by $\mathrm{T} 4$ withdrawal or exogenous administration of recombinant human TSH (rhTSH, Thyrogen, Genzyme Corporation, Cambridge, MA, USA)) to increase the diagnostic sensitivity of $\mathrm{Tg}$ measured on $\mathrm{T} 4$ treatment (onT4-Tg) (5). However, highly sensitive Tg assays (hsTg) have been developed in last years to increase the reliability of onT4-Tg measurement (6). Relevant literature on the issue was recently meta-analyzed showing that onT4-Tg measurement by high-sensitive assays (i.e. functional sensitivity (FS) $\leq 0.1 \mathrm{ng} / \mathrm{mL}$ ) has high negative predictive value (NPV) (i.e. 97-100\%), thus, significantly decreasing the need for stimulated $\mathrm{Tg}$ (7). Table 1 details the results of the main studies on this topic $(1,6,7,8,9,10,11$, $12,13,14)$. However, despite calibration against an international reference standard (BRC457) multiple assays analyzing the same samples report different values due to heterogeneity in both $\mathrm{Tg}$ structure and assays reactivity. Additionally, different protocols are used by manufacturers to define the analytical characteristics of different assays and an assay with a declared higher FS value may have a clinical performance equal to or better than one with a lower declared FS $(15,16,17)$. Accordingly, clinical thyroidologists and laboratory specialists are strongly advised to carefully evaluate the analytical and clinical performance of any newly introduced (highly sensitive) $\mathrm{Tg}$ assay, including a comparison between basal and stimulated values in the same assay and confirm cut-off and decision limits in their own DTC patient populations, ideally by using ROC curve analysis $(16,18,19)$.

As a new fully automated hs-Tg assay was implemented in our center in 2012, here, we investigated the reliability of onT4-Tg measurement with this assay in predicting the early response to treatment and the subsequent outcome in low- and intermediate-risk DTC in comparison to established stimulated Tg measurement. Additionally, the most accurate threshold for onT4-Tg was derived by ROC curve analysis in our clinical population.

\section{Patients and methods}

\section{Institutional treatment and follow-up protocol}

At our thyroid center, DTC patients, excepting those with unifocal DTC $<1 \mathrm{~cm}$ in the largest diameter, underwent (near-)total thyroidectomy with central or lateral neck dissection, depending on risk and intraoperative findings, and a subsequent RRA according to the European Association of Nuclear Medicine (EANM) recommendations (20). Most treatments are performed 4-6 weeks after surgery without introducing T4 replacement (i.e. a certified TSH value $>30 \mathrm{IU} / \mathrm{L}$ is required

Table 1 Diagnostic accuracy data of unstimulated high-sensitive Tg. Predictivity tests were calculated considering the stimulated $\mathrm{Tg}$ as reference standard (positive if $>1 \mathrm{ng} / \mathrm{mL}$ ).

\begin{tabular}{|c|c|c|c|c|c|c|c|c|c|}
\hline Reference & Tg assay & FS $(\mathrm{ng} / \mathrm{mL})$ & Cutoff (ng/mL) & Cases $(n)$ & Se $(\%)$ & Spe (\%) & Acc $(\%)$ & PPV (\%) & NPV (\%) \\
\hline Castagna (8) & Access & 0.1 & 0.1 & 215 & 83 & 86 & 85 & 58 & 95 \\
\hline Castagna (8) & EIASON & 0.02 & 0.02 & 215 & 88 & 86 & 87 & 61 & 97 \\
\hline lervasi (9) & Access & 0.1 & 0.1 & 160 & 79 & 94 & 92 & 65 & 97 \\
\hline Nakabashi (10) & Access & 0.1 & 0.1 & 74 & 75 & 95 & 86 & 92 & 83 \\
\hline Rosario (11) & Access & 0.1 & 0.1 & 178 & 80 & 82 & 81 & 42 & 96 \\
\hline Spencer (6) & Access & 0.1 & 0.1 & 1029 & 96 & 87 & 89 & 74 & 98 \\
\hline Brassard (12) & Access & 0.1 & 0.27 & 215 & 88 & 86 & 87 & 61 & 97 \\
\hline Zöphel (13) & EIASON & 0.02 & 0.02 & 14 & 100 & 77 & 79 & 25 & 100 \\
\hline Trimboli (14) & BRAHMS-LIA & 0.15 & 0.23 & 68 & 88 & 100 & 98 & 100 & 98 \\
\hline Links (1) & Kryptor & 0.15 & 0.15 & 99 & 97 & 64 & 74 & 56 & 98 \\
\hline Giovanella (7)* & Access & 0.1 & 0.1 & 1656 & 91 & 87 & 88 & 70 & 97 \\
\hline Giovanella (7)* & EIASON & 0.02 & 0.1 & 229 & 88 & 85 & 86 & 58 & 97 \\
\hline
\end{tabular}

www.eje-online.org 
in these cases), whereas rhTSH is employed in selected cases on indication of attending physician.

Ablation activities between 1.1 and $2 \mathrm{GBq}$ and 2 and $5.5 \mathrm{GBq}$ are selected, on indication of attending physician, in low- and intermediate-risk patients respectively. Three to seven days after RRA, a post-treatment whole-body scan (PT-WBS) with head and upper mediastinum single photon emission tomography/computed tomography (SPECT/CT) is performed following standard protocols as previously described (21). A PT-WBS showing physiological radioiodine distribution without uptake foci outside the thyroid bed (i.e. remnant) is rated as negative, whereas a PT-WBS showing extra-thyroid non-physiological uptake foci is rated as positive. The latter findings are further clarified by neck US, fine needle aspiration (FNA) and positron emission computed tomography/CT (PET/ $\mathrm{CT}$ ), CT or magnetic resonance imaging (MRI), when indicated. Overall, basing on preoperative assessment, intraoperative findings, pathology report, PT-WBS and additional imaging results patients are classified at high-, intermediate- or low-risk (2). In low-to-intermediaterisk patients, TSH levels are maintained below $0.5 \mathrm{IU} / \mathrm{L}$ until cure is demonstrated and between 0.5 and $2.0 \mathrm{IU} / \mathrm{L}$ later. The response to the initial treatment is evaluated 6-12 months after thyroid ablation by neck US and rhTSH-stimulated Tg testing. An additional diagnostic WBS is performed in patients at intermediate risk and in those with positive TgAb. Primary treatment is considered completed if there is no evidence of residual disease; i.e., negative imaging and rhTSH-Tg levels $<1 \mathrm{ng} / \mathrm{mL}$. In other cases, further examinations were performed and additional treatments (i.e. surgery, radioiodine) were done according to the judgment of the attending physician and multi-disciplinary thyroid board, when needed.

\section{Study design}

All patients who underwent their early DTC posttreatment assessment in our center after the introduction of the new hsTg immunoassay (i.e. 2012) were retrieved from our database. According to the end point of our study, enrolled were patients (1) treated by (near-)total thyroidectomy and RRA, (2) without extra-thyroid uptake foci at post-treatment WBS and (3) classified as at low or intermediate risk (2). Patients with high-risk carcinomas, positive $\operatorname{TgAb}$ before ablation or without a documented assessment of response to therapy were excluded. The response to treatment was assessed as described previously, taking into account rhTSH-stimulated values, and rated as excellent response (ER; rhTSH-Tg $<1 \mathrm{ng} / \mathrm{mL}$, imaging negative), biochemical incomplete response (BIR; rhTSH-Tg $>10 \mathrm{ng} / \mathrm{mL}$, imaging negative), structural incomplete response (SIR; any rhTSH-Tg value, imaging positive) and indeterminate response (IR; rhTSH-Tg $1-10 \mathrm{ng} / \mathrm{mL}$, imaging indeterminate) (2). Patients with no recurrence over time were defined as NED (no evidence of disease). The disease-free survival (DFS) was calculated from the date of RRA to the date of last follow-up (NED patients) or the date of relapse detection.

\section{Laboratory assessment}

Thyrotropin (TSH) was measured with chemiluminescence immunoassays (HYPERsensitive hTSH) on a UniCel DxI 800 automated platform (Beckman Coulter SA, Nyon, Switzerland). The HYPERsensitive hTSH assay is based on the 3rd International Standard (WHO) for human TSH (IRP 81/565) with analytical sensitivity of 0.003 IU/L, FS of $0.01 \mathrm{IU} / \mathrm{L}$ respectively. The TSH normal reference range is $0.40-4.00 \mathrm{IU} / \mathrm{L}$. Serum $\mathrm{Tg}$ and $\mathrm{TgAb}$ were measured on the Kryptor Compact Plus instrument (BRAHMS Thermo Fisher Scientific). This method uses two fluorophores, Lumi4 and Cyanin5.5, detected separately or combined in the same antigen-antibody complex, a method known as the time-resolved amplified cryptate emission (TRACE). The Kryptor hTg-sensitive assay is calibrated against BCR457 international reference standard and the FS (corresponding to inter-assay imprecision of 20\%), had been estimated at $0.15 \mathrm{ng} / \mathrm{mL}$ by the manufacturer (Instruction for use, ThermoFisher). The Kryptor TgAb is standardized against 1st International Reference Preparation 65/93 and the FS had been estimated at $33 \mathrm{IU} / \mathrm{mL}$ by the manufacturer (Instruction for use, ThermoFisher). Then, serum TgAb levels $<33 \mathrm{IU} / \mathrm{mL}$ were considered as negative (22).

\section{Statistical analysis}

Continuous data were analyzed by parametric or nonparametric tests for differences in means or medians, respectively. Mann-Whitney $U$, Wilcoxon test and paired or unpaired $t$-test were used to test the differences between paired or unpaired variables in two groups of patients, when appropriate. $P$ values of 0.05 or less (two-sided test) were considered to indicate the statistical significance. Levels of serum $\mathrm{Tg}<0.15 \mathrm{ng} / \mathrm{mL}$ were considered as $0.15 \mathrm{ng} / \mathrm{mL}$ for statistical analysis. DFS was estimated using the Kaplan-Meier method (23), 
Table 2 Patients' characteristics.

\begin{tabular}{|c|c|}
\hline Characteristics & Values \\
\hline Females/Males & $150 / 51$ \\
\hline Age at diagnosis (years)* & $52.7 \pm 15.0(18-94)$ \\
\hline \multicolumn{2}{|l|}{ Histology } \\
\hline PTC & 176 \\
\hline FTC & 25 \\
\hline \multicolumn{2}{|l|}{ Risk categories } \\
\hline Low & 108 \\
\hline Intermediate & 93 \\
\hline \multicolumn{2}{|l|}{ Radioiodine ablation } \\
\hline Administered activity $(\mathrm{GBq}) * *$ & $2(1.1-5.5)$ \\
\hline
\end{tabular}

FTC, follicular thyroid carcinoma; PTC, papillary thyroid carcinoma; GBq, Giga-Becquerel; risk categories was according to 2015 ATA guidelines. *mean \pm s.D. (range); **median (range)

and differences between curves were analyzed by the log-rank test (24).The degree of association of specific parameters with the presence of disease was analyzed by odds ratio (OR). The predictivity tests, such as sensitivity, specificity, positive (PPV) and negative (NPV) predictive values and accuracy, were calculated by Galen and Gambino tests (25). Continuous variables, such as $\mathrm{Tg}$ levels, were dichotomized by receiver-operating curve (ROC) analysis using the maximum value of Youden's index (J) as the optimal cut-off point (26). All statistical tests were performed by MedCalc Statistical Software, version 15.8 (MedCalc software bvba, Ostend, Belgium).

\section{Ethics}

The protocol was approved by the Advisory Board of Research at Oncology Institute of Southern Switzerland

\section{Correlation between onT4-Tg and rhTSH-Tg}

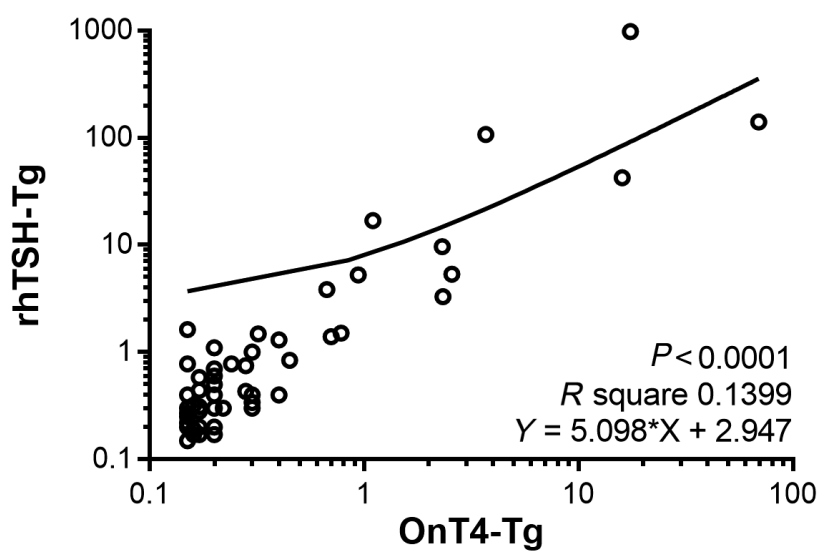

Figure 1

Relationship between onT4 and Tg and rhTSH-Tg values (Log10).
Table 3 Distribution of onT4-Tg strata in different response to treatment classes.

\begin{tabular}{|c|c|c|c|c|}
\hline onT4-Tg (ng/mL) & ER $(n=184)$ & $\operatorname{BIR}(n=2)$ & SIR $(n=7)$ & IR $(n=8)$ \\
\hline$<0.20$ & 174 & - & - & 2 \\
\hline $0.20-1$ & 10 & - & 2 & 5 \\
\hline$>1$ & - & 2 & 5 & 1 \\
\hline
\end{tabular}

$E R$, excellent response; BIR, biochemical incomplete response; SIR, structural incomplete response; IR, indeterminate response.

and the Ethics Committee of Canton Ticino, Bellinzona (Switzerland). All patients gave their informed consent before participating in the study. Our work was conducted according to requirements of Helsinki's Declaration.

\section{Results}

\section{Patient selection}

Two hundred eighty-nine DTCs treated after 2012 were initially found in our database. After exclusion of 43 highrisk patients, 244 low- or intermediate-risk DTC patients were retrieved; among them, 36 (15\%) had preablation positive $\mathrm{TgAb}$ and 9 (4\%) without a documented assessment of response to therapy were also excluded. Then, the final study series comprised 201 patients. Three-fourths were females, and mean age at diagnosis was 52 years. Histological examination showed a PTC/ FTC ratio of 7:1. Median follow-up was 29 months (range from 6 to 130). Patients characteristics are summarized in Table 2 .

\section{Early response to treatment classification}

The response to the initial treatment was assessed by rhTSH-stimulated Tg measurement, neck US and, in more selected cases, DxWBS. Excellent response (ER) was demonstrated in 184 (91.5\%) patients, incomplete response in 9 patients, of which 2 (1\%) had biochemical (BIR) and 7 (3.5\%) structural (SIR) incomplete response. Finally, an indeterminate response (IR) was found in 8 (4\%) patients. A significant relationship was demonstrated

Table 4 onT4-Tg and rhTSH-Tg values recorded in NED and recurrent patients. Values of $\mathrm{Tg}$ are expressed in $\mathrm{ng} / \mathrm{mL}$ and reported as median and ranges.

\begin{tabular}{|c|c|c|}
\hline & onT4-Tg & rhTSH-Tg \\
\hline All cases & $0.17(0.15-69)$ & $0.17(0.15-980)$ \\
\hline NED subjects & $0.17(0.15-2.31)$ & $0.17(0.15-16.9)$ \\
\hline Recurrent cases & $2.33(0.30-69)$ & $5.27(0.40-980)$ \\
\hline
\end{tabular}



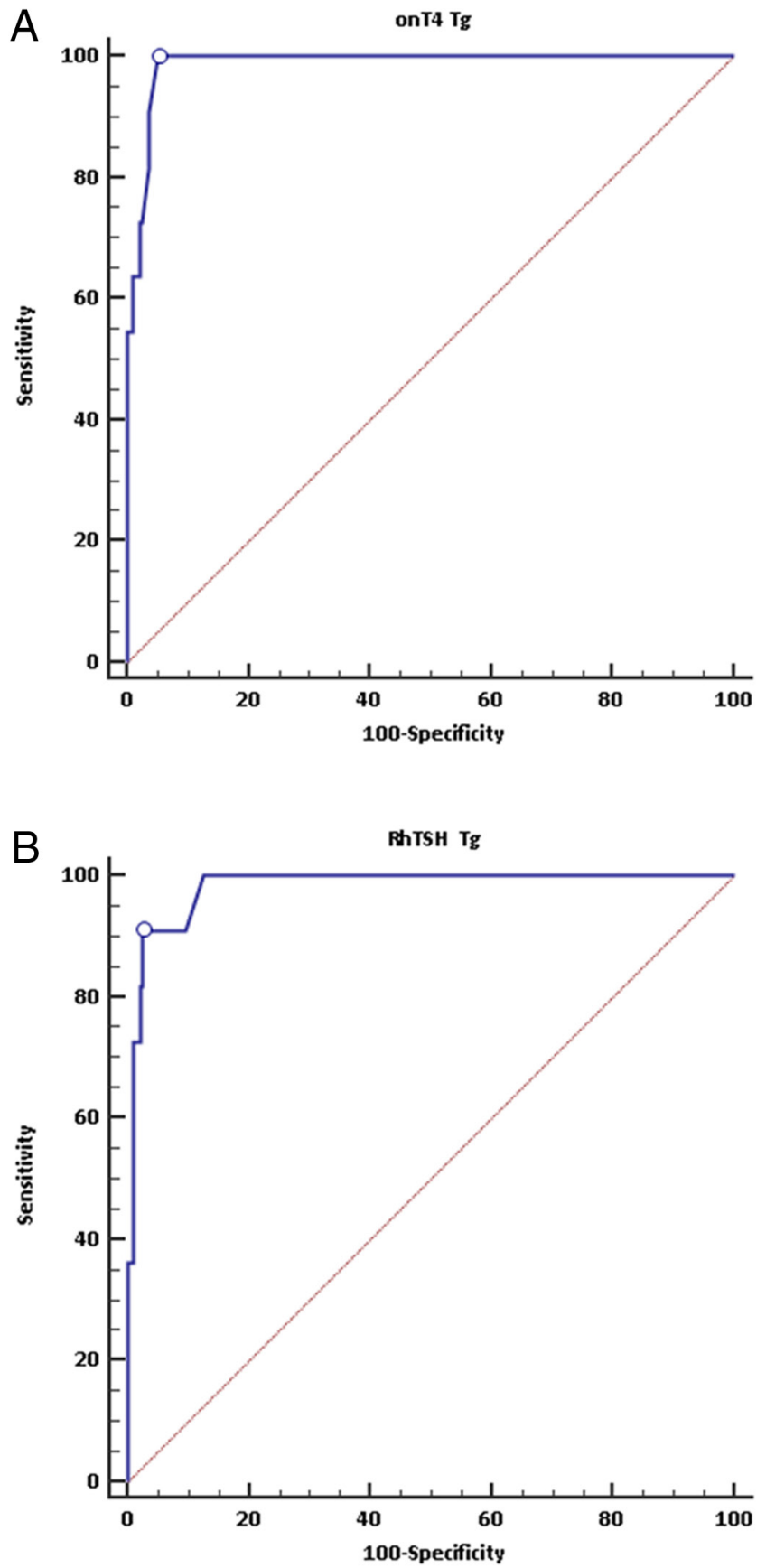

Figure 2

ROC curve analyses of onT4-Tg (A) and rhTSH-Tg (B).

between rhTSH-Tg and onT4-Tg values $(P<.0001)$ (Fig. 1). Seventeen $(8.5 \%)$ patients had rhTSH-Tg values above $1 \mathrm{ng} / \mathrm{mL}$ of which 8 with onT4-Tg $>1.0 \mathrm{ng} / \mathrm{mL}$ and 9 with onT4-Tg between 0.20 and $1.0 \mathrm{ng} / \mathrm{mL}$. Strata of onT4-Tg serum levels (i.e. $<0.20,0.20-1$ and $>1 \mathrm{ng} / \mathrm{mL}$, as per ATA 2015 criteria) in different classes of response to treatment are displayed in Table 3. Of note, onT4-Tg values $<0.20 \mathrm{ng} /$ $\mathrm{mL}$ were recorded in 174/184 (94.5\%) patients with ER,
Table 5 Figure of merits of onT4-Tg and rhTSH-Tg to predict outcome.

\begin{tabular}{|c|c|c|c|c|c|}
\hline & Sensitivity & Specificity & PPV & NPV & Accuracy \\
\hline \multicolumn{6}{|l|}{ onT4-Tg } \\
\hline$<0.20 \mathrm{ng} / \mathrm{mL}^{*}$ & 100 & 92.6 & 44 & 100 & 93 \\
\hline$<0.28 \mathrm{ng} / \mathrm{mL}^{* *}$ & 100 & 94.7 & 52.4 & 100 & 95 \\
\hline \multicolumn{6}{|l|}{ rhTSH-Tg } \\
\hline$<1.0 \mathrm{ng} / \mathrm{mL}^{*}$ & 90.9 & 96.3 & 58.8 & 99.5 & 96.1 \\
\hline$<1.1 \mathrm{ng} / \mathrm{mL}^{* *}$ & 90.9 & 96.7 & 66.6 & 99.5 & 97 \\
\hline
\end{tabular}

*threshold proposed by ATA guidelines, **most accurate cut-off recorded in the present study.

whereas no one among patients with either BIR or SIR showed undetectable (i.e. $<0.20 \mathrm{ng} / \mathrm{mL}$ ) $\mathrm{Tg}$.

\section{Outcome over time according to rhTSH-Tg and onT4-Tg values}

Eleven (5.5\%) patients had structural diseases (10 cervical lymph nodes and 1 lung metastasis) at a mean time of $23 \pm 15$ months since RRA. Two and 9 of these patients were treated by exclusive ${ }^{131}$ I therapy or surgery (followed by adjuvant ${ }^{131}$ I therapy in 4 cases). The remaining 190 patients were disease free (NED) until the last visit of follow-up (mean DFS of $38 \pm 16$ months). At the time of their first follow-up visit after RRA, among 11 recurrent patients 6 had SIR, 3 IR, 1 BIR and 1 ER respectively.

Table 4 details median value and ranges of onT4-Tg and rhTSH-Tg recorded in NED subjects and recurrent patients. Optimized thresholds were determined according to ROC curves analysis at $1.1 \mathrm{ng} / \mathrm{mL}$ for $\mathrm{rhTSH}-\mathrm{Tg}$ (AUC 0.982 , 95\% CI from 0.952 to $0.995, P<0.001)$ and

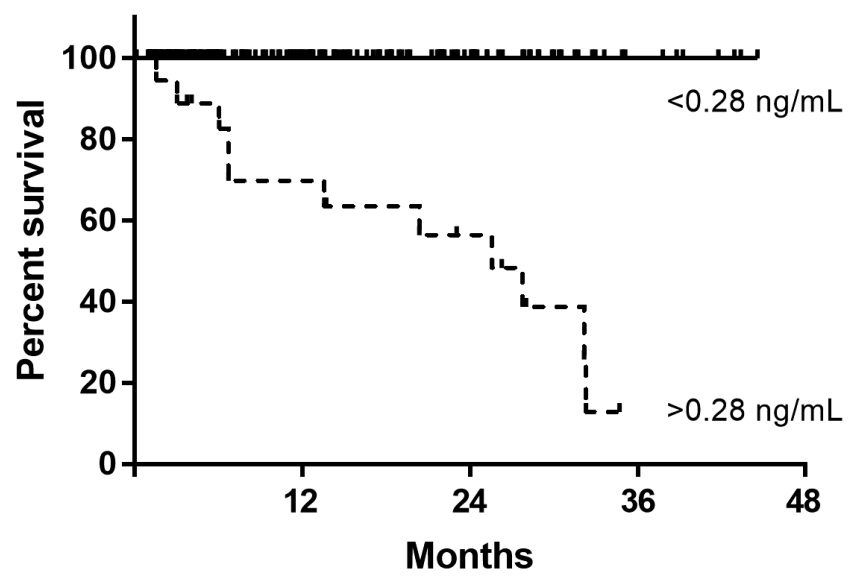

Figure 3

Kaplan-Meier curve of event-free survival according to onT4-Tg value below or above $0.28 \mathrm{ng} / \mathrm{mL}$ as the most accurate cut-off retrieved in our series. 
Schematic illustration of association with response to treatment and outcome over time in low- or intermediate-risk DTC with undetectable on T4-Tg levels at their first follow-up visit

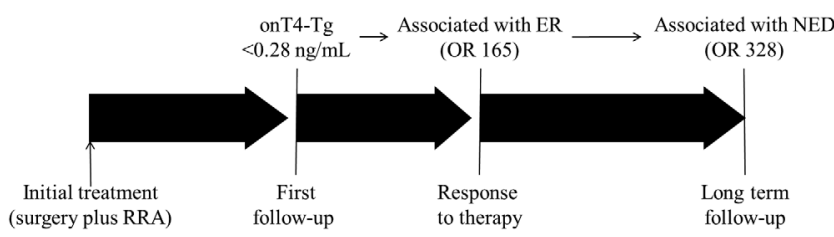

Figure 4

Schematic illustration of association of onT4-Tg with excellent response to initial treatment and outcome over time.

$0.28 \mathrm{ng} / \mathrm{mL}$ for onT4-Tg (AUC 0.987, 95\% CI from 0.960 to $0.998, P<0.001$ ) respectively (Fig. 2). Figure of merits of onT4-Tg and rhTSH-Tg were assessed using ROCderived $(0.28 \mathrm{ng} / \mathrm{mL}$ and $1.1 \mathrm{ng} / \mathrm{mL})$ and ATA 2015 cutoff levels $(0.20 \mathrm{ng} / \mathrm{mL}$ and $1.0 \mathrm{ng} / \mathrm{mL})$ (Table 5$)$. Of note, an undetectable onT4-Tg value (i.e. $<0.28$ or $<0.20 \mathrm{ng} /$ $\mathrm{mL}$ ) predicted a NED status with $100 \%$ NPV. At KaplanMeier analysis, onT4-Tg levels $<0.28 \mathrm{ng} / \mathrm{mL}$ or rhTSH-Tg levels $<1.1 \mathrm{ng} / \mathrm{mL}$ were associated to significantly longer disease-free survival compared to higher values (both $P<0.001)$ as illustrated in Figure 3. Accordingly, having onT4-Tg values $<0.28 \mathrm{ng} / \mathrm{mL}$ at $6-12$ months after RRA was significantly associated to both ER at early follow-up (odds ratio 165 (95\% CI from 32.1 to 847.8 ), $P<0.001$ ) and absence of relapse during the follow-up (odds ratio 328.4 (95\% CI from 18.2 to 5903.6), $P=0.0001$ ) (Fig. 4). Main clinical findings obtained by using the cut-off point of onT4-Tg of $0.28 \mathrm{ng} / \mathrm{mL}$ are illustrated in Figure 5.

\section{Discussion}

Our present study aimed to assess, for the first time to our best knowledge, the clinical effectiveness of the new fully automated high-sensitive Kryptor Tg assay in predicting early response to treatment and outcome over time in low- and intermediate-risk DTC. An earlier report showed a good concordance of Tg levels between Kryptor and the Tg Access assay (Beckmann Coulter, Fullerton, CA, USA) (27). Subsequently, Groen and coworkers found undetectable onT4-Tg in Kryptor assay in 43 of 44 patients with stimulated Tg values $<1 \mathrm{ng} / \mathrm{mL}$ (measured in a different established immunoradiometric assay) (28). In our real-life clinical scenario, rhTSH-Tg levels served as yard-stick in patients' management. Additionally, corresponding onT4-Tg levels were measured allowing a head-to-head comparison. In agreement with the literature, here we did not record disease-related deaths in our series of low- to intermediate-risk DTC patients; $2.5 \%$ of patients were classified as SIR and a 5\% had structural recurrence requiring additional treatments. Moreover, the larger part of cases had excellent response at their first follow-up, and none of them recurred over time. The latter patients had all undetectable onT4-Tg (i.e. $<0.20 \mathrm{ng} /$ $\mathrm{mL}$ ) confirming that the onT4-Tg cut-off proposed by ATA 2015 guidelines (i.e. $>0.1-0.2 \mathrm{ng} / \mathrm{mL}$ ) is highly reliable in identifying disease-free survivors. Furthermore, the optimal onT4-Tg threshold to discriminate patients at higher risk of recurrence from those with high likelihood of NED outcome over time was set at $0.28 \mathrm{ng} / \mathrm{mL}$ by ROC curve analysis. Accordingly, as the most relevant result, a $100 \%$ NPV was achieved in our patients by using this optimized cut-off at time of first follow-up (Fig. 4). A very closed cut-off level was obtained by Brassard and coworkers using hs-Tg Access assay (12). They measured onT4-hsTg 3 months after thyroid ablation. During the median follow-up of 6.2 years, 32 out of 715 patients had a recurrence. Using a cut-off limit at $0.27 \mathrm{ng} / \mathrm{mL}$, as derived by ROC curve analysis, sensitivity and specificity reached $72 \%$ and $86 \%$ respectively, with 20\% PPV and 99\% NPV. However, it should be noted that Brassard and coworkers compared unstimulated Tg levels obtained 3 months after thyroid ablation with stimulated Tg levels obtained 9-12 months later, whereas both basal and stimulated Tg levels should be measured simultaneously 6-12 months after ablation. As Tg levels tend to decline continuously

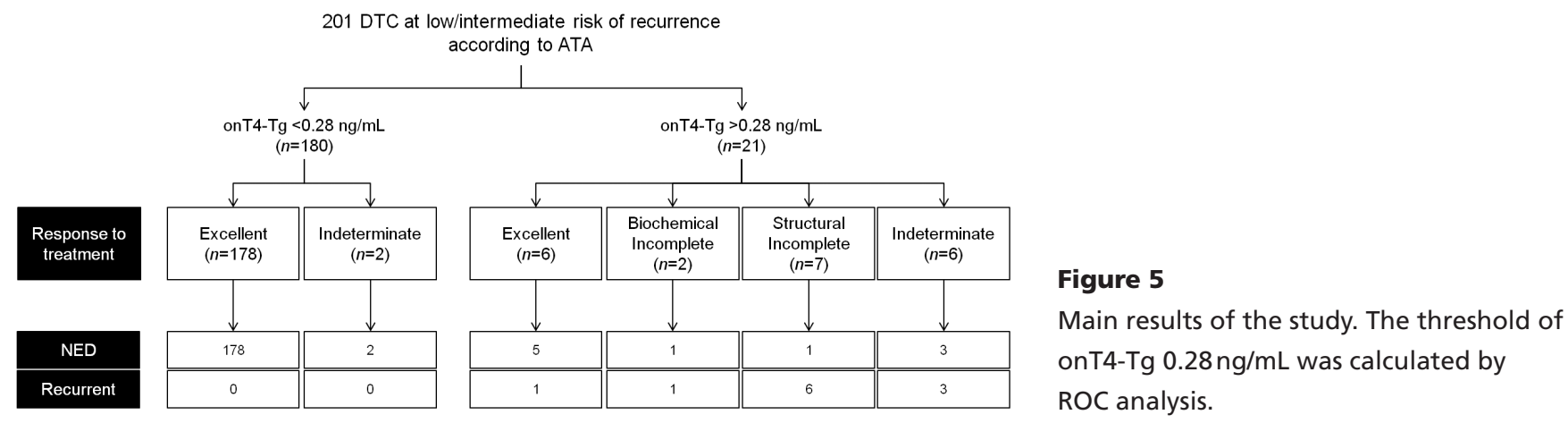

www.eje-online.org 
over time after radioiodine, these data should be interpreted with caution and cannot be compared directly with those obtained in different settings. This further underlines the importance of a careful evaluation of hsTg performance in clinical populations referred to a specific laboratory and also confirms the advantage of optimizing diagnostic cut-offs for any given assay using ROC curve analysis in specific clinical populations $(16,18,19)$. All in all, excluding patients with hsTg $<0.28 \mathrm{ng} / \mathrm{mL}$ from further follow-up would not be related to any risk of missing a subsequent relapse in our series. Indeed, the rate of patients at risk of recurrence would be increased from 5\% in our overall series $(11 / 201)$ to $50 \%$ in those cases with hsTg levels above $0.28 \mathrm{ng} / \mathrm{mL}(11 / 21)$. This approach deserves, of course, confirmations and longterm follow-up remains pivotal. However, our data support a simplified follow-up protocol in patients with low/undetectable onT4-hsTg measurement at their first follow-up visit; i.e., clinical examination and onT4-Tg measurement every 1-2 years (2).

Strengths of our study are the relatively large number of patients, the homogeneous treatment and follow-up protocols with uniform diagnostic methods, risk-assessment and dynamic risk stratification criteria. Additionally, serum Tg levels were measured on a routine basis, using different lots and calibrator in a 5-year period and consequently our data proved robustness in the face of day-to-day assay imprecision and lot-tolot variability. Some potential limitations should be addressed; first, although consecutive patients were enrolled and prospectively managed, the performance of onT4-Tg performance was evaluated by post hoc analysis in comparison with rhTSH-Tg. However, the basal onT4-Tg levels were not taken into account in clinical management and, consequently, relevant biases are unlike. Also, the period of postoperative follow-up of our patients might not be considered as long enough; nevertheless, recurrences have previously been reported to be rare in patients achieving excellent response after thyroid ablation and most relapses occur within the first five years (2). Then, no significant bias might be expected.

\section{Conclusion}

In our series, patients with low- or intermediate-risk DTC could be considered cured when they have Tg levels $<0.28 \mathrm{ng} / \mathrm{mL}$ in Kryptor assay coupled with negative imaging at their first post-ablation visit. Consequently, rhTSH-stimulated $\mathrm{Tg}$ measurement could be safely avoided in these patients. Overall, such data form a reliable reference for larger, prospective and ideally multicentric studies before widely adopting this cut-off limit in clinical practice.

\section{Declaration of interest}

The authors declare that there is no conflict of interest that could be perceived as prejudicing the impartiality of the research reported.

\section{Funding}

This research did not receive any specific grant from any funding agency in the public, commercial or not-for-profit sector.

\section{References}

1 Links TP, van Tol KM, Jager PL, Plukker JT, Piers DA, Boezen HM, Dullaart RP, de Vries EG \& Sluiter WJ. Life expectancy in differentiated thyroid cancer: a novel approach to survival analysis. Endocrine-Related Cancer 200512 273-280. (doi:10.1677/erc.1.00892)

2 Haugen BR, Alexander EK, Bible KC, Doherty GM, Mandel SJ, Nikiforov YE, Pacini F, Randolph GW, Sawka AM, Schlumberger M et al. 2015 American thyroid association management guidelines for adult patients with thyroid nodules and differentiated thyroid cancer: the American thyroid association guidelines task force on thyroid nodules and differentiated thyroid cancer. Thyroid 201626 1-133. (doi:10.1089/thy.2015.0020)

3 Verburg FA, Mäder U, Tanase K, Thies ED, Diessl S, Buck AK, Luster M $\&$ Reiners C. Life expectancy is reduced in differentiated thyroid cancer patients $\geq 45$ years old with extensive local tumor invasion, lateral lymph node, or distant metastases at diagnosis and normal in all other DTC patients. Journal of Clinical Endocrinology \& Metabolism 201398 172-180. (doi:10.1210/jc.2012-2458)

4 Tuttle RM, Tala H, Shah J, Leboeuf R, Ghossein R, Gonen M, Brokhin M, Omry G, Fagin JA \& Shaha A. Estimating risk of recurrence in differentiated thyroid cancer after total thyroidectomy and radioactive iodine remnant ablation: using response to therapy variables to modify the initial risk estimates predicted by the new American Thyroid Association staging system. Thyroid 201020 1341-1349. (doi:10.1089/thy.2010.0178)

5 Wartofsky L. Using baseline and recombinant human TSH-stimulated Tg measurements to manage thyroid carcinoma without diagnostic (131)I scanning. Journal of Clinical Endocrinology \& Metabolism 2000 87 1486-1489. (doi:10.1210/jc.87.4.1486)

6 Spencer C, Fatemi S, Singer P, Nicoloff J \& Lopresti J. Serum basal thyroglobulin measured by a second-generation assay correlates with the recombinant human thyrotropin-stimulated thyroglobulin response in patients treated for differentiated thyroid cancer. Thyroid 201020 587-595. (doi:10.1089/thy.2009.0338)

7 Giovanella L, Treglia G, Sadeghi R, Trimboli P, Ceriani L \& Verburg FA. Unstimulated highly sensitive thyroglobulin in follow-up of differentiated thyroid cancer patients: a meta-analysis. Journal of Clinical Endocrinology \& Metabolism 201499 440-447. (doi:10.1210/ jc.2013-3156)

8 Castagna MG, Tala Jury HP, Cipri C, Belardini V, Fioravanti C, Pasqui L, Sestini F, Theodoropoulou A \& Pacini F. The use of ultrasensitive thyroglobulin assays reduces but does not abolish the need for TSH stimulation in patients with differentiated thyroid carcinoma. Journal of Endocrinological Investigation 201134 219-223. (doi:10.3275/7571)

9 Iervasi A, Iervasi G, Ferdeghini M, Solimeo C, Bottoni A, Rossi L, Colato C \& Zucchelli GC. Clinical relevance of highly sensitive 
Tg assay in monitoring patients treated for differentiated thyroid cancer. Clinical Endocrinology 200767 434-441. (doi:10.1111/j.13652265.2007.02907.x)

10 Nakabashi CC, Biscolla RP, Kasamatsu TS, Tachibana TT, Barcelos RN, Malouf EZ, Andreoni DM, Maciel RM \& Vieira JG. Development, characterization and clinical validation of new sensitive immunofluorometric assay for the measurement of serum thyroglobulin. Archives of Endocrinology and Metabolism 201256 658-665. (doi:10.1590/s0004-27302012000900010)

11 Rosario PW \& Purisch S. Does a highly sensitive thyroglobulin ( $\mathrm{Tg}$ ) assay change the clinical management of low-risk patients with thyroid cancer with $\mathrm{Tg}$ on $\mathrm{T} 4 \mathrm{1ng} / \mathrm{mL}$ determined by traditional assays? Clinical Endocrinology 200868 338-342. (doi:10.1111/j.13652265.2007.03043.x)

12 Brassard M, Borget I, Edet-Sanson A, Giraudet AL, Mundler O Toubeau M Bonichon F Borson-Chazot F Leenhardt L Schvartz C et al. Long-term follow-up of patients with papillary and follicular thyroid cancer: a prospective study on 715 patients. Journal of Clinical Endocrinology \& Metabolism 201196 1352-1359. (doi:10.1210/jc.2010-2708)

13 Zöphel K, Wunderlich G \& Smith BR. Serum thyroglobulin measurements with a high sensitivity enzyme-linked immunosorbent assay: is there a clinical benefit in patients with differentiated thyroid carcinoma? Thyroid 200313 861-865. (doi:10. 1089/105072503322401050)

14 Trimboli P, La Torre D, Ceriani L, Condorelli E, Laurenti O, Romanelli F, Ventura C, Signore A, Valabrega S \& Giovanella L. High sensitive thyroglobulin assay on thyroxine therapy: can it avoid stimulation test in low and high risk differentiated thyroid carcinoma patients? Hormone and Metabolic Research 201345 664-668. (doi:10.1055/s-0033-1345185)

15 Baloch Z, Carayon P, Conte-Devolx B, Demers LM, FeldtRasmussen U, Henry JF, LiVolsi VA, Niccoli-Sire P, John R, Ruf J et al. Guidelines Committee, National Academy of Clinical Biochemistry Laboratory medicine practice guidelines. Laboratory support for the diagnosis and monitoring of thyroid disease. Thyroid 2003 13 3-126. (doi:10.1089/105072503321086962)

16 Schlumberger M, Hitzel A, Toubert ME, Corone C, Troalen F, Schlageter MH, Claustrat F, Koscielny S, Taieb D, Toubeau M et al. Comparison of seven serum thyroglobulin assays in the follow-up of papillary and follicular thyroid cancer patients. Journal of Clinical Endocrinology \& Metabolism 200792 2487-2495. (doi:10.1210/ jc.2006-0723)

17 Giovanella L, Feldt-Rasmussen U, Verburg FA, Grebe SK, Plebani M $\&$ Clark PM. Thyroglobulin measurement by highly sensitive assays: focus on laboratory challenges. Clinical Chemistry and Laboratory Medicine 201553 1301-1314. (doi:10.1515/cclm-2014-0813)
18 Giovanella L, Clark PM, Chiovato L, Duntas L, Elisei R, FeldtRasmussen U, Leenhardt L, Luster M, Schalin-Jäntti C, Schott M et al. Thyroglobulin measurement using highly sensitive assays in patients with differentiated thyroid cancer: a clinical position paper. European Journal of Endocrinology 2014171 R33-R46. (doi:10.1530/EJE-140148)

19 Grebe SKG. Diagnosis and management of thyroid carcinoma: focus on serum thyroglobulin. Expert Review of Endocrinology \& Metabolism 20094 25-43. (doi:10.1586/17446651.4.1.25)

20 Luster M, Clarke SE, Dietlein M, Lassmann M, Lind P, Oyen WJ, Tennvall J, Bombardieri E \& European Association of Nuclear Medicine (EANM). Guidelines for radioiodine therapy of differentiated thyroid cancer. European Journal of Nuclear Medicine and Molecular Imaging 200835 1941-1959. (doi:10.1007/s00259-008-0883-1)

21 Giovanella L, Suriano S, Ricci R, Ceriani L \& Verburg FA. Postsurgical thyroid remnant estimation by $99 \mathrm{mTc}$-pertechnetate scintigraphy predicts radioiodine ablation effectiveness in patients with differentiated thyroid carcinoma. Head Neck 201133 552-556. (doi:10.1002/hed.21490)

22 Verburg FA, Luster M, Cupini C, Chiovato L, Duntas L, Elisei R, Feldt-Rasmussen U, Rimmele H, Seregni E, Smit JW et al. Implications of thyroglobulin antibody positivity in patients with differentiated thyroid cancer: a clinical position statement. Thyroid $2013 \mathbf{1 0}$ 1211-1225. (doi:10.1089/thy.2012.0606)

23 Kaplan EL \& Meier P. Nonparametric estimation from incomplete observations. Journal of the American Statistical Association $1958 \mathbf{5 3}$ 457-481. (doi:10.1080/01621459.1958.10501452)

24 Kalbfleisch JD \& Prentice RL. The statistical analysis of failure time data. New York: John Wiley \& Sons 1980.

25 Galen RS \& Gambino SL. How to determine the predictive value and efficiency of a test when reading a scientific paper. Beyond normality: the predictive value and efficiency of medical diagnosis, 29-40. New York: John Wiley, 1975.

26 Youden WJ. Index for rating diagnostic tests. Cancer 1950 3 32-35. (doi:10.1002/1097-0142(1950)3:1<32::AIDCNCR2820030106>3.0.CO;2-3)

27 Schlageter MH, Toubert ME, Meas T, Bouhassira E, Faugeron I, Vimont V, Thomas E, Theimer C \& Chomienne C. Evaluation of a new thyroglobulin sensitive assay in patients with differentiated thyroid cancer. Clinical Chemistry and Laboratory Medicine 201553 e41-e43. (doi:10.1515/cclm-2014-0662)

28 Groen AH, Klein Hesselink MS, Plukker JT, Sluiter WJ, van der HorstSchrivers AN, Brouwers AH, Lentjes EG, Muller Kobold AC \& Links TP. Additional value of a high sensitive thyroglobulin assay in the follow-up of patients with differentiated thyroid carcinoma. Clinical Endocrinology 2016 Epub ahead of print. (doi:10.1111/cen.13180).

Received 11 December 2016

Revised version received 12 January 2017

Accepted 30 January 2017 